\title{
DOES ORAL STIMULATION PROMOTE THE MATURATION OF THE SUCKING REFLEX IN PRETERM NEWBORNS?
}

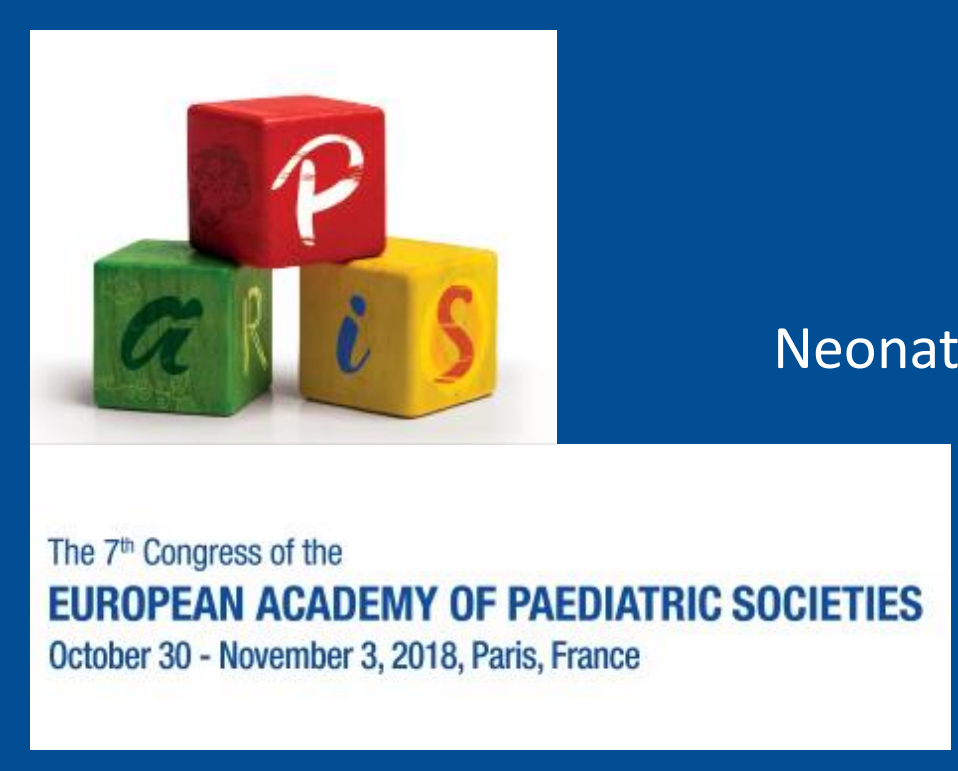

\section{Joana Rombert, Duarte Rebelo, Graça Oliveira}

Neonatology Service, Department of Pediatrics, Hospital Santa Maria, Lisbon (Portugal)

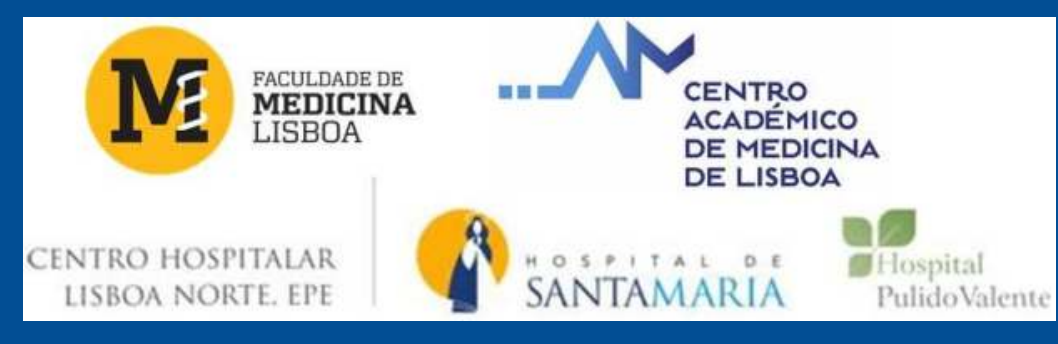

\section{BACKGROUND AND AIMS}

Newborns have specific needs that assist them in their development and enable them to thrive. Feeding is a crucial developmental aspect. The assessment of by preterm infants provides information on the ability of these infants to efficiently and safely of oral feeding.

This study evaluates non-nutritive sucking with pacifier and the start of oral feeding, thus leading to the acceleration of the sucking reflex maturation and the suction-swallowing-breathing coordination, eating autonomy and earlier hospital discharge.

\section{METHODS}

Prospective study. Premature newborns with a gestational age $\geq 29$ weeks were randomly divided in two groups:

- experimental group submitted to a program of oral stimulation (non-nutritive sucking with pacifier associated with oral stimulation) up to 32 weeks of gestational age;

- control group submitted to regular stimulation program (non-nutritive sucking with pacifier).

Criteria for exclusion were ventilation support, neurological impairment and congenital malformations.The oral stimulation was performed by the speech therapist prior to the beginning of the orogastric tube feeding for 10 minutes, 3 times per day.

A scale was applied in order to access the oral motor competences at the beginning, middle and end of the program.

\section{RESULTS}

Table 1. Characterization of the groups

\begin{tabular}{|c|c|c|}
\hline \multirow{2}{*}{ Mean } & \multicolumn{2}{|c|}{ GROUPS } \\
\cline { 2 - 3 } & CONTROL & EXPERIMENTAL \\
\hline $\begin{array}{c}\text { Gestational age } \\
\text { (weeks) }\end{array}$ & 27,5 & 28,1 \\
\hline Weight (g) & 609 & 699 \\
\hline $\begin{array}{c}\text { Oral feeding } \\
\text { achievement } \\
\text { (weeks) }\end{array}$ & 36,5 & 35,7 \\
\hline
\end{tabular}

Results non statistically significant.

- Both groups got a gradual evolution of the oral competences between the first and the third oral motor assessment

\section{Experimental group}

- Acquired eating autonomy 5 days earlier

- Faster ponderal gain, since they also started oral feeding earlier

- Less stress signals

- Results non statistically significant

\section{CONCLUSION}

This study demonstrates that non-nutritive sucking associated with oral stimulation may contribute to speed up the maturation of the sucking reflex in premature newborns $\geq 29$ weeks, leading to earlier discharge. 